\title{
O ESVAZIAMENTO DA ESFERA POLÍTICA NO ROMANCE 1984 DE GEORGE ORWELL
}

\author{
Guilherme de Oliveira Feldens ${ }^{5}$
}

RESUMO: O presente artigo objetiva relacionar as análises de Hannah Arendt em torno de conceitos fundamentais referentes à filosofia política e o Direito com a obra de George Orwell. Com isso, pretende-se demonstrar que a sociedade distópica descrita por Orwell no romance 1984 permanece como um ataque contundente ao conceito do político herdado da tradição ocidental.

Palavras-Chaves: Liberdade; Igualdade; Estado.

\begin{abstract}
This article aims to connect the analyzes of Hannah Arendt about fundamental concepts relative to political philosophy and the Law with the work of George Orwell. Therewith, intended to demonstrate that dystopian society described by Orwell in the novel 1984 remains as a scathing critique to concept of political inherited from western tradition
\end{abstract}

Key Words: Liberty, Equality, State.

\section{INTRODUÇÃO}

A Originalidade do pensamento de Hannah Arendt, em relação a toda tradição do pensamento ocidental, reside no seu objetivo de recuperar a dignidade própria da atividade política, "desprezada" durante toda a sua evolução, desde Platão até a época moderna, e responsável pela interdição do homem na esfera privada. O conflito entre "Filosofia" e "Política", analisado pela autora na extensão de suas obras, e o abismo formado entre os dois termos, acabou por eliminar o que representava ser homem na polis Grega, ou seja, participar ativamente da vida pública e decidir os destinos da comunidade.

\footnotetext{
5 Professor da disciplina de Ciência Política e Teoria Geral do Estado, do Cesuca, Mestre em Direito pela Unisinos, doutorando em Filosofia, pela Unisinos.
} 
Essa análise feita no decorrer de todas as produções da filósofa é muito bem representada pela distopia de George Orwell no livro 1984. Nessa obra, o autor projeta a total submissão do indivíduo e a aniquilação da sua singularidade em razão de um sistema de poder autoritário e onipresente. A sociedade totalitária aqui refletida é descrita através do controle imposto pela tecnologia e por exercícios inusitados de censura. Ambas as obras, convidam seus leitores a refletir não só em relação a massificação e a ausência de liberdade, mas, principalmente, sobre o fracasso do pensamento político ocidental em evitar o esvaziamento político das relações humanas.

\section{AS ORIGENS DO “GRANDE IRMÃO"}

Hannah Arendt expõe que o conflito entre Filosofia e Política teve início no momento em que Platão, por meio da figura do Rei-Filósofo e da distinção entre governante e governados (ou melhor, dos que "sabem" e "não sabem" governar) buscou acabar com a pluralidade dos atores políticos envolvidos. Nesse momento crucial, a imprevisibilidade característica das atividades humanas desaparece, subordinando a política a critérios de aferição de verdade absolutos ${ }^{6}$, com o objetivo de que os filósofos não tivessem o mesmo trágico destino de Sócrates, julgado pela multidão ignorante.

Para a autora, a morte de Sócrates constituiu o momento fundamental, a partir do qual a Política, que até então era a realização máxima da Moral, passou a ser tratada com séria hostilidade pela Filosofia, havendo a repulsa da "persuasão", essencial ao discurso político, bem como de toda capacidade para agir, levando ao esquecimento da definição de homem

\footnotetext{
${ }^{6}$ Segundo Hannah Arendt (1979, p. 289), “o conflito entre verdade e política surgiu historicamente de dois modos de vida diametralmente opostos - a vida do filósofo, tal como interpretada primeiramente por Parmênides e, depois, por Platão, e o modo de vida do cidadão. Às flexíveis opiniões do cidadão acerca dos assuntos humanos, os quais por si próprios estão em fluxo constante, contrapunha o filósofo a verdade acerca daquelas coisas que eram por sua mesma natureza sempiternas e das quais, portanto, se podiam derivar princípios que estabilizassem os assuntos humanos. Por conseguinte, o contrário da verdade era a mera opinião, equacionada com a ilusão; e foi esse degradamento da opinião o que conferiu ao conflito sua pungência política; pois é a opinião, e não a verdade, que pertence à classe dos pré-requisitos indispensáveis a todo poder . Todo governo assenta-se sobre a opinião, disse James Madison, e nem mesmo o mais autocrático tirano ou governante pode alçar-se algum dia ao poder, e muito menos conserva-lo, sem o apoio daqueles que têm modo de pensar análogo. Ao mesmo tempo, toda pretensão, na esfera dos assuntos humanos, a uma verdade absoluta, cuja validade não requeira apoio do lado da opinião, atinge na raiz mesma toda a política e todos os governos.”
} 
como "animal Político". 7 Assim sendo, "a maior parte da filosofia política, desde Platão, poderia facilmente ser interpretada como uma série de tentativas de encontrar fundamentos teóricos e meios práticos de evitar inteiramente a política” (Arendt, 1981, p. 234).

A obra de George Orwell ilustra de maneira genial as consequências dessa situação ao apresentar uma sociedade caracterizada pela eliminação da diversidade e pelo afastamento de todos os indivíduos da esfera política. A história narrada em 1984 evidencia o esfacelamento da correlação das atividades humanas (Labor, Trabalho, e Ação), no qual a atividade do labor é considerada hegemônica, libertando-se da condição de elemento da esfera privada como fora concebida pela Antiguidade Grega. Essa condição resultou no desaparecimento da esfera pública, espaço voltado para a individualidade e para a liberdade humana, local em que os homens podiam mostrar o que realmente eram. No mundo moderno, o espaço público, exclusivo a excelência política, cede lugar à glorificação do labor (Arendt, 1981, p. 234).

É frente a este cenário, que se deve levar em conta a importância das relações estabelecidas no espaço público como atividades dignificadoras do ser humano, pois é no espaço público que o homem desenvolverá relações únicas, marcadas por sua singularidade, onde cada ação tem sua importância por ser fruto da atividade livre de cada indivíduo específico. Além disso, as preocupações de George Orwell servem para questionar a importância pública dada aos interesses privados na modernidade e a compreensão da liberdade como livre arbítrio, ocasionando as condições ideais para o surgimento de governos limitadores da liberdade política, que agregam rodos os indivíduos sob uma mesma opinião ${ }^{8}$, sem o sentido de "comunidade" Grego, eliminando qualquer traço de pluralidade (marca fundamental da autêntica atividade política).

\footnotetext{
${ }^{7}$ Para Aristóteles (2005, p. 8), “é evidente que toda Cidade está na natureza e que o homem é naturalmente feito para a sociedade política. Aquele que, por sua natureza e não por obra do acaso, existisse sem nenhuma pátria seria um indivíduo detestável, muito acima ou muito abaixo do homem, segundo Homero: Um ser sem lar, sem família e sem leis. Aquele que fosse assim por natureza só respiraria a guerra, não sendo detido por nenhum freio e, como uma ave de rapina, estaria sempre pronto para cair sobre os outros. Assim, o homem é um animal cívico, mais social do que as abelhas e os outros animais que vivem juntos".

${ }^{8}$ Esse aspecto é muito bem descrito na seguinte passagem do livro 1984: "De um membro do partido, por outro lado, não se pode tolerar nem o menor desvio de opinião a respeito do assunto menos importante. O membro de partido vive, do berço à cova, sob os olhos da Polícia do pensamento. Mesmo quando está sozinho jamais pode ter certeza de seu isolamento. Onde quer que esteja, dormindo ou acordado, trabalhando ou descansando, no banho ou na cama, pode ser examinado sem aviso e sem saber que o examinam. Nada do que ele faz é indiferente. Suas amizades, seus divertimentos, sua conduta em relação a esposa e aos filhos, a expressão de seu rosto quando está só, as palavra que murmura no sono, e até os movimentos característicos de seu corpo, é tudo ciosamente analisado" (Orwell, 2009, p.154).
} 


\section{Liberdade, Ação e Justiça}

Segundo Hannah Arendt (1979, p.192), a liberdade "é, na verdade, a razão pela qual os homens convivem em organizações políticas. Sem ela, a vida política como tal seria destituída de significado". Desta forma, a existência da liberdade só pode ser constatada na interação com os outros. O homem excluído, fora das relações sociais e humanas, fica despido da sua própria dignidade, pois seus atos não atingirão o resto da comunidade, o deixando em total situação de isolamento. Nesse contexto, até uma simples troca de olhares com um colega, como no caso do personagem Winston, pode significar "um acontecimento memorável, na solidão amuralhada em que se era obrigado a viver" (Orwell, 2009, p. 11)

Regressando à Antiguidade Grega, Hannah Arendt demonstra que a liberdade política, enraizada na polis, caracterizava-se pela inexistência de governantes e governados e pela existência da pluralidade de participantes em condições de igualdade, qualidades estas esquecidas pela tradição filosófica do pensamento ocidental. Segundo a autora:

a tradição filosófica distorceu, em vez de esclarecer, a própria ideia de liberdade tal como ela é dada na experiência humana ao transpô-la de seu campo original, o âmbito da política e dos negócios humanos em geral, para um domínio interno, a vontade, onde ela seria aberta à auto-inspeção. (Arendt, 1979, p. 191.)

Dessa forma, enquanto que a polis Grega caracterizou-se pela existência de um espaço no qual a liberdade podia manifestar-se, proporcionando aos homens um espaço adequado ao diálogo florescer, na modernidade, o local de origem da liberdade foi colocado no interior do homem, em sua vontade e em seu pensamento, perdendo dessa maneira qualquer relação para com a pluralidade humana que constitui o âmbito político. 9

Para a autora, a liberdade não é livre arbítrio, mas está identificada com a esfera da ação política, ou seja, os homens são livres ao exercitarem ação e decidirem conjuntamente

\footnotetext{
${ }^{9}$ Para Arendt (1991, p. 200), “a liberdade política distingue-se da liberdade filosófica por ser claramente uma qualidade do eu posso, e não do eu quero. Uma vez que é possuída pelo cidadão, e não pelo homem em geral, só pode se manifestar em comunidades, onde o relacionamento dos muitos que vivem juntos é, tanto no falar quanto no agir, regulado por um grande número de raports - leis, costumes, hábitos e similares. Em outras palavras, a liberdade política só é possível na esfera da pluralidade humana."
} 
seus destinos, sendo que a perspectiva moderna de liberdade, como algo interior, contribui profundamente para a destruição e a deformação das diversas capacidades humanas, em especial, a capacidade de exercer a atividade política enquanto atividade humana por excelência (exclusivamente humana, por sinal), a qual somente pode ser exercida na esfera pública, na qual aparece a pluralidade de diálogos entre iguais.

Assim sendo, é a Ação política a atividade caracteristicamente humana, pois é mediante palavras e atos que o sujeito se revela aos demais, aparecendo como indivíduo, como um agente que é portador de uma história individual e que se comunica com seus semelhantes. "Ser" humano, portanto, é aparecer ao mundo dos outros, apresentar-se a eles, com todas as suas particularidades, adquirindo reconhecimento mútuo. Uma sociedade que nega a ação política sacrifica a história pessoal e o individualismo dos cidadãos.

Segundo Orwell (p. 156) uma sociedade assim constituída sacrifica sua humanidade, fazendo com que o indivíduo

\begin{abstract}
não tenha emoções pessoais nem lapsos de entusiasmo. Supõe-se que viva num frenesi contínuo de ódio aos inimigos estrangeiros e aos traidores internos, de gozo ante as vitórias e de auto-degradação perante o poderio e a sabedoria do partido. Os descontentamentos produzidos por essa vida nua e insatisfatória são deliberadamente purgados e dissipados por estratagemas tais como os Dois Minutos de ódio, e as especulações que poderiam vir a induzir uma atitude de cepticismo ou de rebeldia são antecipadamente suprimidas pela disciplina aprendida na infância.
\end{abstract}

Cabe ainda ressaltar, que o poder deveria ser caracterizado como a consequência da ação conjunta dos homens, com o discurso e a persuasão como atributos principais. O poder deveria pertencer ao grupo ${ }^{10}$, livre de qualquer traço de violência ${ }^{11}$, contrariamente a configuração de poder feita pela tradição do pensamento político ocidental (caracterizada no livro 1984), que desde Platão se deu com traços de violência. Analisando estes aspectos, há

\footnotetext{
${ }^{10}$ Segundo a autora (Arendt, 1973, p. 123) o "poder corresponde à capacidade humana não somente de agir mas de agir de comum acordo. O poder nunca é propriedade de um indivíduo; pertence a um grupo e existe somente enquanto o grupo se conserva unido. Quando dizemos que alguém está no poder, queremos dizer que está autorizado por um certo número de pessoas a atuar em nome delas. No momento em que o grupo do qual se originou a princípio o poder (potestas in populo, sem o povo ou um grupo na há poder), desaparecer, seu poder some também."

${ }^{11}$ A autora deixa bem claro (Arendt, 1973, p. 132) que "em termos de política, não basta dizer que poder e violência não são a mesma coisa. Poder e violência se opõem; onde um deles domina totalmente o outro está ausente. A violência aparece onde o poder está em perigo, mas se a permitirem seus próprios caminhos, resulta no desaparecimento do poder."
} 
de se recordar que o "direito" à vida pública foi obstruído no processo de constituição das sociedades modernas, servindo de fundamento para modelos de organização como o Estado totalitário descrito por George Orwell, marcado pela mera administração da sociedade, acabando praticamente com todos os espaços para agir e opinar.

Segundo palavras da própria autora (Arendt, 1973, p. 79)

o próprio governo representativo está em crise hoje; em parte porque perdeu, com o decorrer do tempo, todas as praxes que permitam a real participação dos cidadãos, e em parte porque atualmente sofre gravemente da mesma doença que os sistemas de partidos - burocratização e tendência do bipartidarismo em não representar ninguém exceto as maquinas dos partidos.

Dentro deste quadro, perde-se o caráter conflituoso da política em troca de uma política e de um comportamento normatizado e previsível, no qual o interesse pela participação e pelo engajamento no mundo comum são substituídos pela atitude de "representantes" que defendem apenas interesses privados que não dizem respeito aos aspectos da política. Tal realidade acaba por configurar o declínio da esfera pública, resultando em atitudes meramente subjetivas do homem frente ao mundo, culminando na "alienação do mundo" característica das sociedades de massas, caracterizada pela incapacidade do homem moderno de exercer atividade política enquanto atividade por excelência.

A ficção de George Orwell serve para lembrar a necessidade ainda atual de propor formas de organização que estimulem o maior interesse e participação política por parte dos cidadãos em todas as instâncias públicas, fugindo da concepção de política como administração das necessidades vitais. Impede-se, assim, a atomização social, a indiferença política, e o risco de desaparecimento do exercício ativo da liberdade política, responsáveis pelo avanço dos apelos de governos totalitários. Segundo a autora, a legitimidade do poder e das instituições políticas depende da vontade contínua dos cidadãos em apoiar o poder por um 
contrato efetivo, que os vincula reciprocamente, e não da formação racional de uma vontade coletiva única, contrária a condição humana. ${ }^{12}$

\section{A Igualdade Como Objetivo Político}

$\mathrm{Na}$ obra 1984, George Orwell apresenta uma sociedade altamente opressora que fundamenta todo seu aparelho opressor e coercitivo em "prol" de um princípio de igualdade natural dos homens. Arendt recusa terminantemente esse princípio, responsável pela sustentação de praticamente todos os estatutos jurídicos modernos, pois, segundo autora, a pluralidade humana assegura que os homens, ao invés de serem iguais desde o nascimento, sejam vistos como realmente são: distintos e singulares. É nestes termos, portanto, que para Arendt a igualdade tem lugar no corpo político:

toda essa esfera do que é meramente dado, relegada à vida privada na sociedade civilizada, é uma permanente ameaça à esfera pública, porque a esfera pública é tão consistentemente baseada na lei da igualdade como a esfera privada é baseada na lei da distinção e da diferenciação universal. A igualdade, em contraste com tudo o que se relaciona com a mera existência, não nos é dada, mas resulta da organização humana, porquanto é orientada pelo princípio da justiça. Não nascemos iguais; tornamo-nos iguais como membros de um grupo por força da nossa decisão de nos garantirmos direitos reciprocamente iguais. A nossa vida política baseia-se na suposição de que podemos produzir igualdade através da organização, porque o homem pode agir sobre o mundo comum e mudá-lo e construí-la juntamente com os seus iguais. (Arendt, 1978. p. 181)

Concluí-se, portanto, a partir do pensamento da autora, que a igualdade é um objetivo humano que precisa ser construído, por meio da organização política e da distribuição de direitos (Duarte, 2000, p. 100). Trata-se de uma igualdade política e não de uma igualdade natural. Apenas com a construção de uma igualdade política na comunidade é possível

\footnotetext{
12 Segundo Arendt (1973, p. 78), “todos os contratos, convênios e acordos se apóiam na reciprocidade, e a grande vantagem da versão horizontal do contrato social é que esta reciprocidade liga cada um dos membros a seus colegas cidadãos. Esta é a única forma de governo em que o povo é mantido unido pela força de promessas mutuas e não por reminiscências históricas ou homogeneidade étnica (como no Estado-Nação) ou pelo Leviathan de Hobbes que intimida a todos e desta forma une a todos. Para Locke, isto significava que a sociedade permanece intacta mesmo que o governo seja dissolvido ou rompa seus acordos com a sociedade transformando-se numa tirania."
} 
garantir ao homem dignidade e participação como sujeito ativo do destino da polis, impedindo o seu isolamento. ${ }^{13}$

Assim sendo, a igualdade não pode significar um nivelamento com base em qualquer critério, não podendo se fundamentar em uma suposta igualdade inata, que impede de aprendermos com as diferenças, eliminando a pluralidade e nivelando os cidadãos por baixo; distinguindo-se frontalmente da igualdade de Arendt, que garante à política a existência de um caráter nitidamente conflituoso, resultado dos desejos de os homens superarem uns aos outros por meio de atos e palavras.

Essa igualdade universal e abstrata tem suas raízes fundamentadas no idealismo que atravessa toda a filosofia ocidental. Rosenzwieg, em sua obra Estrela da Redenção, estabelece a tese de que é o idealismo que inevitavelmente leva aos regimes totalitários (Rosenzwieg, 1997, p. 362). O idealismo, por um lado, coloca o sentido fora da realidade, produzindo um desprezo pela experiência (Mate, 2005, p. 145). Por outro, converge-se necessariamente ao monismo, reduzindo toda a pluralidade a unicidade do conceito. Assim sendo, Rosenzwieg conclui (1997, p. 370) que, para o idealismo, não deveria haver nenhum problema individual para com a morte. Porém, o individuo que morre não entende que se salva no todo. Todo ser humano tem uma experiência existencial angustiante com a morte ${ }^{14}$. Para entender o valor absoluto da vida e derrubar as teses idealistas e totalitárias deve-se levar em conta a experiência fundamental de angústia individual perante a morte e o sofrimento (Rosenzwieg, 1997, p. 372).

\footnotetext{
${ }^{13}$ Conforme expõe a autora (Arendt, 1981, p. 31) "a polis diferenciava-se da família pelo fato de somente conhecer iguais, ao passo que a família era o centro da mais severa desigualdade. Ser livre significava ao mesmo tempo não estar sujeito ás necessidades da vida nem ao comando de outro e também não comandar. Não significava domínio, como também não significava comandar."

${ }^{14}$ Segundo Reyes Mate (2005, p. 149), “o que o Estado não pode pretender com suas guerras é que a justificação e racionalização das mortes dos indivíduos que comportam sejam explicadas com o argumento de que, nessa disponibilidade para a morte, a morte do indivíduo passa do ser nada para algo, passa do ser uma morte natural para um sacrifício por um valor superior. Com essa falácia se rebela Rosenzweig ao detectar na angústia diante da morte a recusa de uma imposição totalitária. Na experiência da angústia esconde-se um princípio de resistência contra o projeto filosófico de reduzir a morte individual para pura insignificância concedendo ao Todo que representa o domínio sobre a morte e, portanto, sobre a vida. A apologia do todo não se baseia na sedução do grande sobre o pequeno, nem do geral sobre o singular, mas no monismo na redução da variedade do mundo à unicidade do conceito, quer dizer, ao idealismo".
} 
A tese de Rosenzwieg é muito bem apresentada na parte final do 1984. Quando O’Brien tortura Winston, tudo que passa na mente do torturado é seu desespero diante do desconhecido e a possibilidade de ter traído Júlia:

O cotovelo! Caíra de joelhos, quase paralisado, protegendo com a mão o cotovelo atingido. Tudo explodira numa luz amarela. Inconcebível, inconcebível que um só golpe produzisse tamanha dor! O amarelo se foi e ele pôde enxergar os dois a contemplá-lo. $\mathrm{O}$ guarda ria-se das suas contorções. Ao menos uma dúvida fora esclarecida. Nunca, por nenhuma razão, se poderia desejar que a dor aumentasse. Da dor, só se podia desejar uma coisa, que parasse. Nada no mundo era tão horrível como a dor física. Em face da dor não há heróis, não há heróis, ele pensou e tornou a pensar, torcendo-se no chão, segurando á toa o braço esquerdo invalidado (Orwell, 2009, 178).

O texto de Orwell evidencia a trágica preocupação com a forma de pensar idealista do mundo ocidental, responsável por fazer com que a política produza regimes nos quais qualquer coisa pode ser justificada em nome do todo (Mate, 2005, p. 70). A superação desta concepção, contrária à condição do ser humano, juntamente com a retomada da possibilidade de atuação política de cada homem, com as suas particularidades, resgata a dignidade de se pertencer a uma comunidade, trazendo consigo, além de uma participação concreta, a responsabilidade na construção conjunta de seus destinos.

\section{Considerações Finais.}

A importância dos conceitos de ação política, liberdade, igualdade política e participação plena dos cidadãos em todas as instâncias da esfera pública, apresentados por Hanna Arendt, reside fundamentalmente, para os dias de hoje, nas possibilidades de análise e crítica das estruturas sociais modernas, e de seus marcos característicos como a apatia política e o conformismo dos cidadãos frentes as responsabilidades políticas; a existência marcante e o predomínio de um senso comum em termos de política e economia, que contraria a condição essencial da pluralidade humana; e a infiltração de interesses econômicos e privados na política, resgatando, assim, a necessidade do exercício de cidadania. 
A obra de George Orwell, da mesma forma, resiste à prova do tempo, comprovando sua atualidade ao levantar fontes de questionamento contra uma realidade de completa exclusão e separação dos homens. Tal quadro permanece sendo refletido nos dias de hoje no total descaso das instituições públicas com os problemas da população, que não consegue sequer ser ouvida. Os "conflitos públicos" não entram nos fóruns, nos Tribunais ou em repartições públicas, formando o quadro ideal para arbitrariedades, pois ao serem impedidos de agir, os cidadãos tornam-se meros objetos, vítimas de acontecimentos dos quais não conseguem fazer parte como sujeitos. Nota-se, portanto, que no pensamento de George Orwell encontra-se uma base crítica atual ao sistema estatal e jurídico, que através da destruição das relações comunitárias, da perda do exercício da cidadania e da participação plena dos cidadãos na esfera pública, ocasiona a restrição do espaço público, limitando a liberdade política dos cidadãos. 


\section{REFERÊNCIAS}

ARENDT, Hanna. Entre o Passado e o Futuro. São Paulo: Perspectiva, 1979. .A Condição Humana. Rio de Janeiro: Forense Universitária, 1981.

.O Sistema Totalitário. Lisboa: Publicações Dom Quixote, 1978.

. Crises da República. São Paulo: Perspectiva, 1973.

.A Vida do Espírito, O Pensar, O Querer, O Julgar. Rio de Janeiro: Relume Dumará, 1991.

ARISTÓTELES. Politica. São Paulo: Nova Cultural, 2005.

DUARTE, André. O Pensamento à Sombra da Ruptura: Política e Filosofia em Hanna Arendt. São Paulo: Paz e Terra, 2000.

MATE, Reyes. Memórias de Auschwitz. São Leopoldo: Nova Harmonia, 2005.

ORWELL, George. 1984. São Paulo: Companhia das Letras, 2009. 
ROSENZWEIG, Franz. La Estrella de la Redención. Salamanca: Ediciones Síguem, 1997. 